\title{
Research on Chinese Traditional Sculpture and Modern Sculpture of Ceramic Pottery of Artistic Expression
}

\author{
Xiaofei Liu \\ School of Arts, Xi'an University, Xi'an 710065, China. \\ 517707074@qq.com
}

Keywords: Traditional sculptural pottery; modern sculptural ceramics; artistic expression.

\begin{abstract}
The sculpture is a branch of ceramic pottery, referring to the pottery works with sculptural feature. It also has the characteristics of sculpture and pottery. Through artistic expression of traditional Chinese pottery sculpture of artistic expression of modern sculpture and pottery to elaborate.
\end{abstract}

\section{Introduction}

The modern high-tech economy of the traditional handicraft industry is undergoing tremendous change, but prominent Chinese Jingdezhen ceramics precipitation with history for thousands of years now makes traditional ceramic handicraft still play a huge role. Traditional techniques and traditional decorations in the form of widely attracted many astute contemporary artists to come here to create, traditional values and ideologies create a decorative techniques and production skills in today's society and forms spawned by the collision of contemporary art and fusion.

\section{Traditional Chinese Pottery Sculpture of Artistic Expression}

\subsection{Functional Performance of Chinese Traditional Sculptural Pottery Symbolic.}

Referring to the sense of having witchcraft, we have to mention Yangshao culture of "Human head jar." Yangshao ruins of " Human head jar," the opening the bottle is made carvings of human head, the head of the image portrayal of vivid detail, and especially hair hairdo is scored very delicate. Miaodigou culture female head clay pots, the whole Painted is expensive, personal, female head and neck as the spout, women's hair style, shape of a tile officials are rhythmic (Fig. 1).

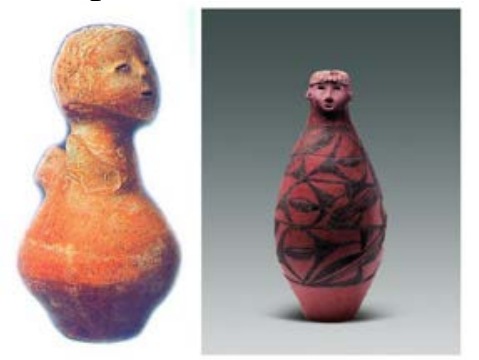

Fig. 1 "Human head jar" and "Female head clay pot"

Secondly to say is the "tombs funerary objects" to use. Representative significance of it is the Qin Terracotta Warriors and Horses. Terra is the earliest archaeological pottery. The "Warriors" is used for funerary dolls. Speaking from the production process, it is produced by a mold out of the terracotta warriors and horses and then by secondary processing into shape and the size, but if you look closely you will find their expression are in different styles. Of course, they were also relaxed and composed, lively and playful image of the young soldier, perhaps he is a true portrayal of the soul Reviewed craftsmen (Fig. 2). 


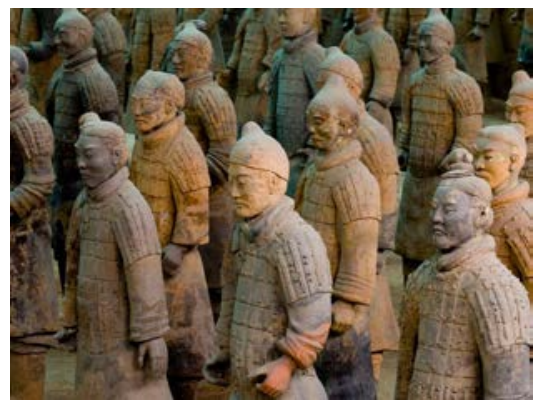

Fig. 2 "Qin Terracotta warriors"

\subsection{Practical Performance of Chinese Traditional Sculptural Pottery Artistic Value.}

Practical Performance of the Artistic Value of the Porcelain.

Ding baby pillow from overall, has vivid and unique, delicate white glaze, the glaze layer uniform, bright lesson. Craftsmen shape the image of a boy lying on the couch by realistic approach. It pillows children back side, clasping his arms pad at the head, eyes straight ahead, his right hand was also dedicated a silk sash-like fabric, decorated on a hydrangea, Hydrangea pattern is clearly visible on the silk sash in the Hydrangea each side made a bow very cute. Children of two leg backward tilt, overlap together. Natural look of the baby, innocent naughty, lifelike, reflects Ding Song Dynasty porcelain artist superb skills (Fig. 3).

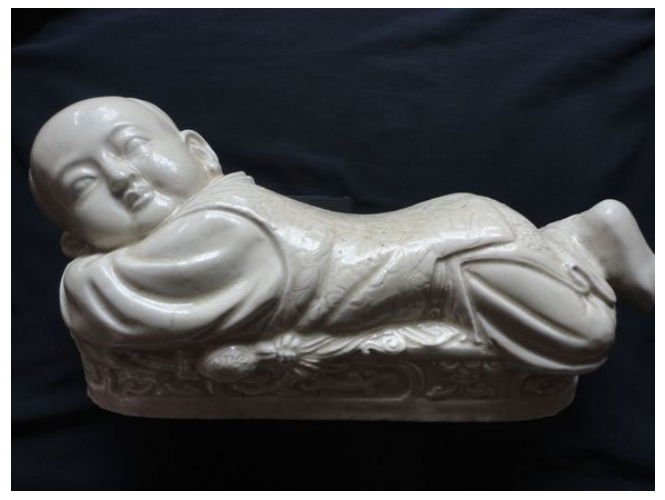

Fig. 3 "Baby pillow" of Ding Yao

Practical Performance of the Artistic Value of the Toy.

Ceramic toys are either directly from the system or made by hand. Profit in inch high, but vivid, interesting taste, for which reason people like it. These vivid, naive children's toys are full of meaning and Folklore strong guitar-like connotation. Toys intended primarily for children to carry around in your hand to play or evil; some are used for worship Gods use. Such as the annual meeting or Taoist temple to worship on behalf of tablets. In some places in the spring, the ceramic toys are scattered in the ground, in order to a good harvest (Fig. 4).

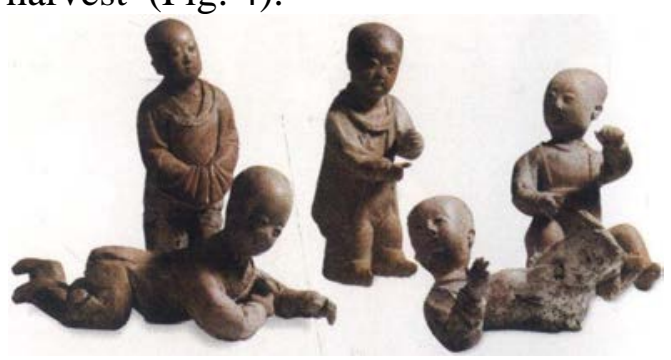

Fig. 4 Clay Toys

Traditional Chinese Pottery Sculpture of the Traditional Folk Life Performance.

Art is born of life, it changes the lives, works of art of different periods also reflect different people at different stages of life and quality of living conditions is a true portrayal of history. Traditional sculptural art pottery is close to life, to reflect the folk customs, religion, culture and art when people pursue a more direct and obvious. It reflects folk live performance, but also an important manifestation of traditional sculptural pottery. It can be manifestations of folk life from the creation of the main themes, decorative patterns into two categories. 


\section{Chinese Artistic Expression of Modern Sculpture Pottery}

Today, with changing times and social development, China has become a modern sculpture of ceramic pottery in modern Chinese unique one. Its manifestations and performance techniques are unique. Especially in a variety of scientific and technological innovation by the West under the influence of modern ceramics, innovative ideas and artistic innovation in China's booming rise, making the craft and aesthetics of traditional ceramic sculpture at this time also undergo improvements and changes.

\subsection{Focus on Ceramic Materials Mud Language.}

Many types of mud, the characters they demonstrated are not exactly the same. Coarse clay (such as sagger soil) can exhibit a rustic feeling rough and boldness, gives rise to more vigorous, original, unadorned, without modification of pure beauty. Zhou Guozhen is a very good use of the crude material performance characteristics of different personalities animals' ceramists, his work "old ape", "gorilla", "Shen pig", "owl", are the natural texture of the sagger soil using, with concise summary of expression, desalination works artificial carving traces, so that he can works to achieve a return to the realm of art. In contrast, the fine quality of the energy performance of a fine mud, the Commission bowls feelings, giving produce plain, elegant, rustic beauty (Fig. 5).

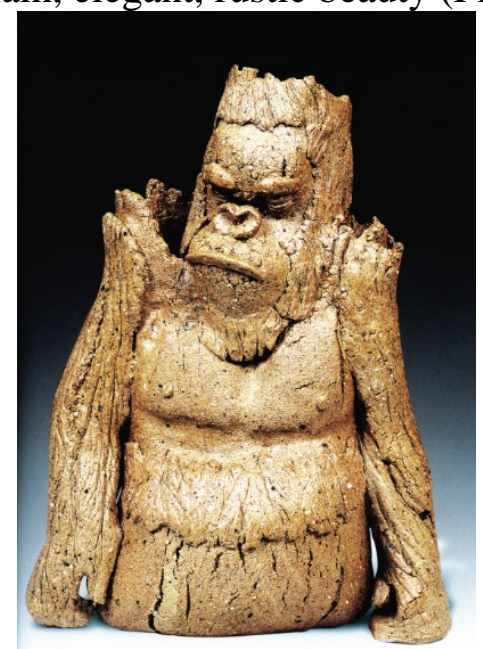

Fig. 5 "Big Monkey King”

\subsection{Focus on Emotional Expression of the Potters.}

Chinese modern potters clearly know that with a focus on spiritual content and language form of unity both, from the level of thoughts and feelings, seek natural expression language, is the only way possibly to produce high-quality pottery works. Based on their own life experience and experience for art from different angles artistic thinking, exploring personalized way, they are no longer pursuing the surface in the form of interest, but the heart a word corresponding to the language and spirit of the character form: their concern is no longer empty of too abstract themes.

\section{Chinese Modern Pottery Sculpture of a New Artistic Expression}

Claire says, "Art is the validity of such a long time of constant content. After generations, people rediscover the emotional content, and again giving it meaning and life," Chinese traditional sculptural pottery although already quit the stage of history, its intrinsic spiritual value is worthy of future generations to learn. Modern potters will often use traditional themes as their own creative material, although one of the major traditional auspicious patterns decorative sculptural forms of traditional pottery, in modern sculptural ceramic art often potters use in their own artistic creation

\subsection{China Modern Ceramic Sculpture of the Traditional Method of Creation of New Diagnostic} Interpretation.

Traditional ceramic sculpture is mainly dominated by hand-molding and mold. The early ancestors of the fire in the applications found in the soil at a high temperature firing can be hard, so there the earliest pottery came. Because of the lack of doctors behind productivity tools, all of the 
pottery are handmade dough molding, in addition to life outside there are utensils used for worship statues used, artifacts, toys and so on. With the invention and use of the mold, it was found that the production of plastic mold for the production of high efficiency, tire shape and more neat than the hand, so they gradually replaced hand molding method, including terracotta, pottery, etc. are used molding method produced.

\subsection{Chinese Modern Sculptural Pottery New Explore into the Body Language of Materials.}

Modern sculpture of ceramic arts is in the constantly updated concept. Comprehensive and binding material, are reorganized by innovative artists into new media art forms. In modern times, expressing ideas is above all. When a single material can not be expressed when the idea of the artist's expression, a comprehensive application materials become one of the best forms of expression, materials intervention sculptural ceramic art, is a potter in a particular social and historical and cultural environment consciously responding to movement in art expression, is a potter new values, new ideas, new thinking substance presented.

\section{Summary}

In this paper, through the description of Chinese traditional arts of pottery and sculpture modern sculpture of elaborate pottery, we obtain modern sculptural ceramics on the basis of inheriting the tradition are at the new development. In traditional Chinese pottery sculpture of a long historical process, practicality and functionality are always the first attribute of its production, rather than a personality culture.

\section{References}

[1] R. Chompu-inwai and T. Apinun, "The application of Material Flow Cost Accounting for loss reduction in the pottery and decorative ceramics production process," Logistics, Informatics and Service Sciences (LISS), 2015 International Conference on, Barcelona, 2015, pp. 1-6.

[2] A. Karasik, "A complete, automatic procedure for pottery documentation and analysis," 2010 IEEE Computer Society Conference on Computer Vision and Pattern Recognition - Workshops, San Francisco, CA, 2010, pp. 29-34.

[3] M. Fujikawa, F. Oda, K. Moriyasu, S. Fuchi and Y. Takeda, "The New Verification Method of Authenticity for Pottery and Porcelain Products: Application of the Artifact-Metrics Technology," Computer Software and Applications Conference (COMPSAC), 2013 IEEE 37th Annual, Kyoto, 2013, pp. 714-715.

[4] L. Ma, C. Sheng, J. Pan and T. Li, "Design of a ceramic mud argil content detector," Electronic Measurement \& Instruments, 2009. ICEMI '09. 9th International Conference on, Beijing, 2009, pp. 1-949-1-952. 